\title{
Aortic wall proteomic analysis in spontaneously hypertensive rats with a blood pressure decrease induced by 6-week load-free swimming
}

\author{
HONG FENG $^{1 *}$, HAIYING LI $^{2 *}$, DERONG ZHANG ${ }^{3}$, YUNGANG ZHAO $^{1}$, NING JIANG ${ }^{1}$, \\ XIAOLING ZHAO ${ }^{2}$, YU ZHANG ${ }^{4}$, JUNZHEN TAN ${ }^{5}$, WEN FANG ${ }^{6}$, YONG ZHANG ${ }^{1}$ and WEI LIU ${ }^{2}$ \\ ${ }^{1}$ Tianjin Key Laboratory of Exercise Physiology and Sports Medicine, Tianjin University of Sport, Tianjin 300381; \\ ${ }^{2}$ Institute of Health and Environmental Medicine, Tianjin 300050; ${ }^{3}$ Department of Health and Exercise Science, \\ Tianjin University of Sport, Tianjin 300381; ${ }^{4}$ Department of Family Planning, The Second Affiliated Hospital of Tianjin \\ Medical University, Tianjin 300211; ${ }^{5}$ School of Integrative Medicine, Tianjin University of Traditional Chinese \\ Medicine, Tianjin 300193; ${ }^{6}$ Department of Graduate, Tianjin University of Sport, Tianjin 300381, P.R. China
}

Received March 6, 2015; Accepted May 21, 2015

DOI: $10.3892 /$ br. 2015.488

\begin{abstract}
Decreased arterial compliance is one of the earliest detectable manifestations of adverse structural and functional changes within the vessel wall in hypertension. The proteomic approach is a powerful technique to analyze a complex mixture of proteins in various settings. Physical activity level was negatively associated with blood pressure. Sixteen 4-week-old male spontaneously hypertensive rats (SHR) and 16 Wistar-Kyoto (WKY) rats were randomly divided into four groups: i) SHR exercise group, ii) SHR rest group, iii) WKY exercise group and iv) WKY rest group. In the SHR and WKY exercise groups, rats were treated with a 6-week load-free swimming protocol ( $1 \mathrm{~h} /$ day, 5 days/week). The blood pressure of the rats was tested by the $\mathrm{CODA}^{\mathrm{TM} 2}$ single non-invasive blood pressure measurement appliance. After the 6-week swimming protocol, the total aorta excluding abdominal aorta was extracted. The proteins were separated by two-dimensional gel electrophoresis and identified via LC-mass spectrometry (MS)/MS. After 6-week load-free swimming, blood pressure decreased in the SHRs. Compared with sedentary SHRs, 11 spots on the 2D-gel showed a significant difference in exercised SHRs. Nine of these were chosen for further identification. There were 5 upregulated proteins (long-chain specific acyl-CoA dehydrogenase, heat shock protein $\beta-1$, isocitrate dehydrogenase subunit $\alpha$, actin, $\alpha$ cardiac muscle 1 preprotein and calmodulin isoform 2 ) and 4 downregulated proteins (adipocyte-type fatty acid-binding
\end{abstract}

Correspondence to: Dr Wei Liu, Institute of Health and Environmental Medicine, 1 Dali Road, Tianjin 300050, P.R. China E-mail: liuwei9668@126.com

${ }^{*}$ Contributed equally

Key words: aortic wall, proteomic analysis, hypertension, 6-week load-free swimming protein, tubulin $\beta-2 \mathrm{C}$ chain, $78 \mathrm{kDa}$ glucose-regulated protein precursor and mimecan). Proteomics is an effective method to identify the target proteins of exercise intervention for hypertension.

\section{Introduction}

Hypertension is the most frequent chronic disease in the developed world. It is a multisystemic disease that affects the heart and kidneys among other organs. The overall functional, structural and biochemical alterations in vasculature have been extensively studied during hypertension, but the molecular mechanisms remain unclear. Decreased arterial compliance is one of the earliest detectable manifestations of adverse structural and functional changes within the vessel wall (1). It has been shown that the proteomic approach is a useful technique to analyze a complex mixture of proteins in various settings, usually by combining two-dimensional electrophoresis and mass spectrometry (MS) (2). Bian et al (3) recently analyzed the proteome of aorta from spontaneously hypertensive rats (SHR). They found that SHR showed a significant alteration in the aortic wall protein profile compared with normal rats.

Exercise is a key antihypertensive therapy. It is reported that the physical activity level was negatively associated with blood pressure. In addition, the blood pressure can be decreased with long-term physical activity. Blood pressure of SHRs undergoing the physical activity protocol was lower than that of the normal SHRs. The functional and structural alterations in vasculature occurred in hypertensives following exercise training. Aerobic physical activity may alter the aortic wall remodeling to adapt the artery to a hyperkinetic blood flow resulting in alterations of the extracellular matrix modulation and vascular resistance. Certain data showed that the aorta wall thickness was smaller in the SHRs undergoing an aerobic physical activity protocol for 20 weeks (4). Furthermore, the alteration in the aortic wall protein profile was shown in SHRs with exercise. Kimura et al (5) demonstrated that the 4-hydroxynonenal and 3-nitrotyrosine levels in the aorta of running-trained SHR 
were significantly lower than those in the non-exercised group. Bobillier et al (6) indicated that there was an increase in the aortic metallothionein amounts in swimming-trained SHRs. Swimming-trained SHRs showed an apelin-immunoreactivity level in the aorta (7), but the overall aortic wall protein profile remained unclear.

The present study used two-dimensional polyacrylamide gel electrophoresis (2D-PAGE) for protein separation and identified some of the proteins by MS. Nine proteins were identified that had a significant difference between swimming-exercised SHRs and non-exercised SHRs. The molecular mechanism of exercise decreasing the blood pressure is also discussed.

\section{Materials and methods}

Animals and research design. Studies were performed with male SHRs and their normotensive counterpart Wistar-Kyoto (WKY) (180-200 g in weight). The animals were housed in double cages in a temperature-controlled room $\left(21-22^{\circ} \mathrm{C} ; 50-60 \%\right.$ humidity) with a 12 -h reversed light cycle and provided free access to food and tap water. All the experiments were approved by the Institutional Review Board of the Tianjin University of Sport Research Animal Resource Center (Tianjin, China).

Each type of rat was divided into an exercise-trained and sedentary control group. Thus, the rats were randomly allocated into four groups $(n=8$ each): i) Sedentary WKY (SED-WKY), ii) exercised WKY (EX-WKY), iii) sedentary SHR (SED-SHRs) and iv) exercised SHR (EX-SHRs).

Exercise training. During week 1, the exercise-trained SHR and WKY were acclimated to 15-min load-free swimming in a basin (water depth of $50 \mathrm{~cm}$, water temperature of $36^{\circ} \mathrm{C}$ ). The duration was progressively increased. At the end of week 1 the rats were able to swim for $60 \mathrm{~min}$. This intensity was maintained during the rest of the training period ( 5 days/week for 6 weeks). Sedentary rats were kept under the same living conditions as the exercise-trained rats, except for the training.

Measurement of blood pressure. Weekly systolic blood pressure (SBP) and diastolic blood pressure (DBP) were measured with the $\mathrm{CODA}^{\mathrm{TM} 2}$ non-invasive single channel BP measuring instrument (Zenda Instrument Co., Ltd., Austin, TX, USA).

Sample preparation, two-dimensional electrophoresis and analysis. Total protein was extracted only from the aorta (abdominal aorta was not included). Briefly, aorta samples were pulverized after being frozen by liquid nitrogen. Pulverized tissue powder was homogenized in lysis buffer $(9 \mathrm{M}$ urea, $2 \mathrm{M}$ thiourea, $4 \%$ CHAPS, $2 \%$ IPG buffer, $40 \mathrm{mM}$ dithiothreitol and $40 \mathrm{mM}$ Tris-base) and centrifuged at 20,000 x g for $45 \mathrm{~min}$ at $4^{\circ} \mathrm{C}$. The supernatant was collected as a protein sample and the concentration was determined by the Bradford protein assay (8).

A sample containing $250 \mu \mathrm{g}$ of protein was applied to the first-dimensional isoelectric focusing in the ReadyStrip immobilized $\mathrm{pH}$ gradient strips (18 cm; pH 3-10 NL). Separation of proteins in the second dimension was achieved by SDS-PAGE (10\%). Two-dimensional gels were stained by coomassie brilliant blue and scanned by Imagescanner (GE-Amersham Biosciences Corp., Piscataway, NJ, USA). Digitized images were recorded and imported to ImageMaster 2D Platinum 6.0 software (GE Healthcare Life Sciences, Fairfield, CT, USA). Analysis was performed matching the spots from different gels of different animals for each group.

Trypsin digestion and protein identification by MS. Protein spots of interest were excised manually from the gels and digested with trypsin as described previously (9). The identification of protein was performed by peptide mass fingerprinting using LCQ Deca XP (Thermo Electron Corp, San Jose, CA, USA) mass spectrometers.

Statistical analyses. Results of blood pressure are expressed as means \pm standard error of the mean. Comparisons between multiple groups were performed by or two-way analysis of variance. Tests were performed using the SPSS 12.0 software package (SPSS, Inc., Chicago, IL, USA). Proteomic statistical analysis was performed using TurboSEQUEST 3.3 software (Bioworks, Thermo Electron, Marietta, OH, USA), which includes a statistical package. Spots were tested with the t-test. $\mathrm{P}<0.05$ was considered to indicate a statistically significant difference.

\section{Results}

Blood pressure decrease in SHR induced by 6-week load-free swimming. The blood pressure of 12-week-old SED-SHR was significantly higher than that of the age-matched SED-WKY [SBP, $195.78 \pm 11.46$ vs. $126.63 \pm 11.70 \mathrm{mmHg}$; DBP, $144.05 \pm 21.47$ vs. $85.43 \pm 9.73 \mathrm{mmHg}$; mean arterial pressure (MAP), $166.32 \pm 11.93$ vs. $104.59 \pm 16.23 \mathrm{mmHg} ; \mathrm{P}<0.01]$. Contrasted to that of SED-SHR, the blood pressure of the EX-SHR that underwent 6-week load-free swimming was reduced (SBP, $163.44 \pm 12.90$ vs. $195.78 \pm 11.46 \mathrm{mmHg}$; DBP, $121.19 \pm 12.61$ vs. $144.05 \pm 21.47 \mathrm{mmHg}$; MAP, $134.13 \pm 18.31$ vs. $166.32 \pm 11.93 \mathrm{mmHg} ; \mathrm{P}<0.01)$. Six-week load-free swimming did not reduce the blood pressure in exercised WKY rats (SBP, $123.92 \pm 12.55$ vs. $126.63 \pm 11.70 \mathrm{mmHg}$; DBP, $85.20 \pm 12.54$ vs. $85.43 \pm 9.73 \mathrm{mmHg}$; MAP, $98.28 \pm 9.19$ vs. $104.59 \pm 16.23 \mathrm{mmHg})$. The results are shown in Table I.

Protein expression profile. Comparison among SED-WKY, EX-WKY, SED-SHR and EX-SHR was performed by the replicate group option and the statistical software package of ImageMaster 2D Platium 6.0. Spot quantification was normalized on the basis of the total staining density of the image to compensate for any variation in protein loading and development level of coomassie brilliant blue staining. The differential expression was calculated for every spot that could be matched in all the samples of $\geq 1$ group.

From all the spots resolved in the $\mathrm{pH} 4$ to 7 range by two-dimensional electrophoresis of aortic wall tissue from WKY and SHR, the same 453 well-resolved spots were focused on in a 12 - to $90-\mathrm{kDa}$ molecular weight, as previously analyzed (6). Significant differences were shown in 11 analyzed spots in EX-SHR versus SED-SHR $(\mathrm{P}<0.05)$; 5 increased and 6 decreased. Ten protein spots were found to 
Table I. Effects of 6-week load-free swimming on the blood pressure in SHR and WKY rats.

\begin{tabular}{|c|c|c|c|c|c|c|c|c|}
\hline \multirow[b]{2}{*}{ Pressure } & \multicolumn{2}{|c|}{ SED-WKY (n=8) } & \multicolumn{2}{|c|}{ EX-WKY $(n=8)$} & \multicolumn{2}{|c|}{ SED-SHR $(n=8)$} & \multicolumn{2}{|c|}{ EX-SHR $(n=8)$} \\
\hline & 0 weeks & 6 weeks & 0 weeks & 6 weeks & 0 weeks & 6 weeks & 0 weeks & 6 weeks \\
\hline SBP & $119.62 \pm 8.03$ & $126.63 \pm 11.70$ & $117.14 \pm 12.15$ & $123.92 \pm 12.55$ & $153.17 \pm 9.91^{\mathrm{a}}$ & $195.78 \pm 11.46^{\mathrm{a}, \mathrm{b}}$ & $153.17 \pm 17.08$ & $163.44 \pm 12.90^{c}$ \\
\hline DBP & $93.79 \pm 6.90$ & $85.43 \pm 9.73$ & $87.58 \pm 7.40$ & $85.20 \pm 12.54$ & $110.69 \pm 11.92^{\mathrm{a}}$ & $144.05 \pm 21.47^{\mathrm{a}, \mathrm{b}}$ & $112.74 \pm 7.65$ & $121.19 \pm 12.61^{\mathrm{c}}$ \\
\hline MAP & $81.25 \pm 7.31$ & $104.59 \pm 16.23$ & $75.17 \pm 6.79$ & $98.28 \pm 9.19$ & $97.67 \pm 11.40^{\mathrm{a}}$ & $166.32 \pm 11.93^{\mathrm{a}, \mathrm{b}}$ & $98.70 \pm 6.30$ & $134.13 \pm 18.31^{\mathrm{c}}$ \\
\hline
\end{tabular}

${ }^{a} \mathrm{P}<0.01$ for SED-SHR versus SED-WKY; ${ }^{\mathrm{b}} \mathrm{P}<0.05$ for 6 vs. 0 weeks in SED-SHR; ${ }^{\mathrm{P}} \mathrm{P}<0.01$ for EX-SHR versus SED-SHR. Data are mean mmHg \pm standard deviation. SHR, spontaneously hypertensive rat; WKY, Wistar-Kyoto; SED-WKY, sedentary WKY; EX-WKY, exercised WKY; SED-SHR, sedentary SHR; EX-SHR, exercised SHR; SBP, systolic blood pressure; DBP, diastolic blood pressure; MAP, mean arterial pressure.

Table II. Identification of the differentially expressed proteins in EX-SHR versus SED-SHR.

\begin{tabular}{|c|c|c|c|c|c|}
\hline Protein number & Ms identification & NCBInr index score & Top score & $\mathrm{pI}$ & Mw (kDa) \\
\hline $\mathrm{S} 2$ & Adipocyte-type fatty acid-binding protein & gil2494405 & 155 & 7.71 & 14.699 \\
\hline S4 & Tubulin $\beta-2 \mathrm{C}$ chain & gil5174735 & 276 & 4.79 & 49.799 \\
\hline S5 & $78 \mathrm{kDa}$ glucose-regulated protein precursor & gil25742763 & 261 & 5.07 & 72.302 \\
\hline S6 & Mimecan & gil157824206 & 133 & 5.85 & 34.048 \\
\hline S7 & Long-chain specific acyl-CoA dehydrogenase & gil6978431 & 228 & 7.63 & 47.842 \\
\hline S8 & Heat shock protein $\beta-1$ & gil94400790 & 147 & 6.12 & 22.808 \\
\hline S9 & NAD subunit $\alpha$ & gil16758446 & 130 & 6.47 & 39.588 \\
\hline $\mathrm{S} 10$ & Actin, $\alpha$ cardiac muscle 1 preprotein & gil4885049 & 116 & 5.23 & 41.992 \\
\hline S11 & Calmodulin isoform 2 & gil71664 & 62 & 4.09 & 16.696 \\
\hline
\end{tabular}

EX, exercised; SHR, spontaneously hypertensive rats; SED, sedentary; NAD, isocitrate dehydrogenase.
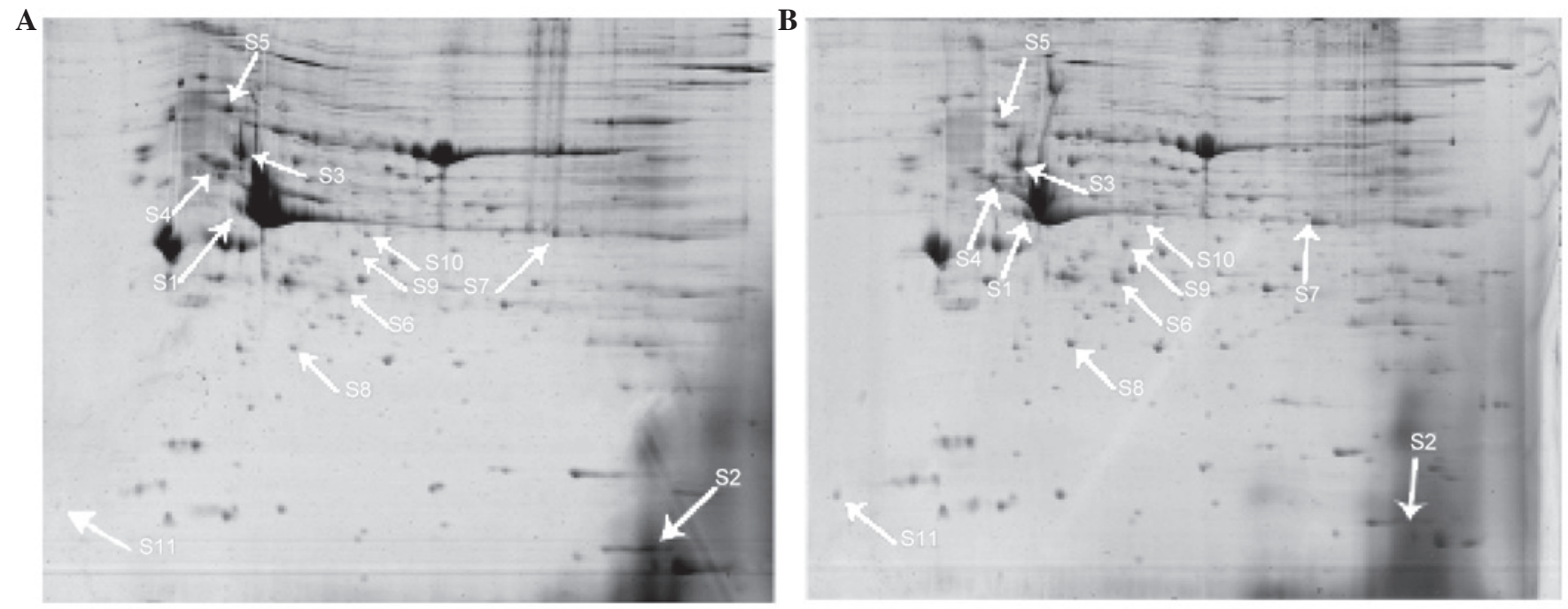

Figure 1. Two-dimensional gel images of (A) sedentary spontaneously hypertensive rats (SED-SHR) and (B) exercised SHR (EX-SHR). Proteins that were significantly differentially expressed $>2$-fold are indicated with arrows and number. Nine of the proteins were identified using LC-mass spectrometry (MS)/MS.

change significantly in EX-SHR versus EX-WKY $(\mathrm{P}<0.05)$; 5 increased and 5 decreased. There were 8 protein spots that showed significant differences in EX-WKY versus SED-WKY $(\mathrm{P}<0.05) ; 1$ increased and 7 decreased. Thirteen protein spots were found to change significantly in EX-WKY versus SED-WKY $(\mathrm{P}<0.05) ; 11$ increased and 2 decreased. Accurate protein identification was achieved for 9 spots and failed in 2 in EX-SHR versus SED-SHR. The spots are all indicated with arrows in Fig. 1.

Protein identification. All the 11 spots were excised from the rehydrated gels and subjected to in-gel trypsin digestion for subsequent identification by MS. Nine of them contained peptides and 2 failed identification. Five upregulated spots and 
4 downregulated spots were identified finally. The results are shown in Table II.

\section{Discussion}

The aim of the present study was to screen and identify proteins secreted by the aortic wall as potential biomarkers of susceptibility to exercise-induced blood pressure decreasing. SHR and WKY rats were chosen for the contrasting susceptibilities of different blood pressure level. The results also showed that the blood pressure is normal in WKY rats while hypertension occurs in SHR. After 6-week load-free swimming, the blood pressure decreased significantly in SHR, which was consistent with other studies $(10,11)$.

Recent research found that aerobic physical activity may alter the aortic wall remodeling to adapt the artery to a hyperkinetic blood flow resulting in alterations of the extracellular matrix modulation and vascular resistance (4). Certain studies identified that the expression of several proteins changed in the aortic wall induced by exercise in SHRs $(5,6)$. However, the overall aortic wall protein profile remains unclear.

In the present study, the proteomics of the aortic wall in SED-SHRs and EX-SHRs were presented to explore the molecular mechanism for exercise decreasing the blood pressure. Differentially expressed proteins were detected in the aortic wall from SED-SHRs compared with EX-SHRs. Five upregulated proteins and 4 downregulated proteins were obtained in the aortic wall of EX-SHRs. An association between these proteins and decreasing blood pressure was suggested.

Spot S2 was identified as the adipocyte-type fatty acid-binding protein (A-FABP). A-FABP was downregulated 12.8-fold in the EX-SHR group compared with the SED-SHR group. FABPs are abundantly expressed 14-15 kDa proteins that reversibly bind hydrophobic ligands (12). A-FABP is highly expressed in adipocytes and macrophages (13). It is involved in insulin resistance, lipid metabolism and atherosclerosis. Expression of A-FABP is highly regulated during differentiation of adipocytes and its mRNA is transcriptionally controlled by fatty acids, PPAR- $\gamma$ agonists and insulin $(14,15)$.

Spot S4 was identified as tubulin $\beta-2 \mathrm{C}$ chain. Tubulin $\beta-2 \mathrm{C}$ chain was downregulated 2.3 -fold in the EX-SHR group compared with the SED-SHR group. Exercise training decreased $\beta$-tubulin protein expression in the kidney of chronic heart failure (CHF) rats, which suggests that exercise training can significantly improve the renal dysfunction in CHF rats (16).

Spot S5 was identified as the $78 \mathrm{kDa}$ glucose-regulated protein precursor. In the present study, glucose-regulated protein 78 precursor was downregulated 2.2 -fold in the EX-SHR group compared with the SED-SHR group as determined by 2D-PAGE. Glucose-regulated protein 78 (GRP78) is a well-characterized molecular chaperone that is ubiquitously expressed in mammalian cells. GRP78 is best known for binding to hydrophobic patches on nascent polypeptides within the endoplasmic reticulum and for its role in signaling the unfolded protein response. Studies have shown that GRP78 is expressed on the cell surface in numerous tissue types in vitro and in vivo. GRP78 disregulation is also indicated in atherosclerotic, thrombotic and auto-immune disease (17). Previous studies showed that the levels of GRP78 were upregulated in the soleus muscle of Wistar rats and the brain of Alzheimer's disease mice adhering to treadmill running for 3 to 4 months duration $(18,19)$. However, investigators found that treadmill running for 5 days did not increase GRP78 expression in cardiac muscle (20).

Spot S6 was identified as mimecan. Mimecan was downregulated 2.1-fold in the EX-SHR group compared with the SED-SHR group as determined by 2D-PAGE. Mimecan (also known as osteoglycin) belongs to the family of small leucine-rich proteoglycans, a group of 11 proteins, characterized by leucine-rich repeats in their central domain. These proteins are located in the extracellular matrix and are important for the regulation of the matrix structure, but also in the regulation of cell cycle and growth factor actions (21). Mimecan in the aorta was mainly produced by VSMCs and perivascular fibroblasts. A downregulation was confirmed following the onset of arteriogenesis (22). Its expression was also regulated during atherosclerosis in patients and animals. Differential expression of mimecan was identified in VSMCs during neointima formation and in atherosclerosis plaques $(23,24)$. The downregulation of osteoglycin expression in the collateral arteries of rabbits subjected to femoral artery occlusion indicated a function of osteoglycin as a negative regulator of the mitotic activity in the wall of collateral arteries (22).

Spot $\mathrm{S} 7$ was identified as the long-chain specific acyl-CoA dehydrogenase (LCAD). In the present study, LCAD was upregulated 2.0-fold in the EX-SHR group compared with the SED-SHR group as determined by 2D-PAGE. LCAD catalyzes the $\alpha, \beta$-dehydrogenation of acyl-CoAs, the initial step of mitochondrial $\beta$-oxidation. LCAD has been shown to be involved in the degradation of branched-chain fatty acids originating from peroxisomal catabolism of phytanic acid, but LCAD is also able to handle straight-chain and certain monounsaturated acyl-CoAs (25). The phenotype of the $\mathrm{LCAD}^{-/-}$mouse is characterized by unprovoked sudden death, fasting and cold intolerance, hypoketotic hypoglycaemia and marked fatty changes in liver and heart (26). A previous study found that the 3-hydroxyacylcarnitines were absent in $\mathrm{LCAD}^{-/}$tissues and a profound deficiency of acetylcarnitine was observed in $\mathrm{LCAD}^{-/}$hearts, indicating that the cardiomyopathy in the $\mathrm{LCAD}^{-/}$mouse is caused primarily by a severe energy deficiency in the heart, stressing the important role of LCAD in cardiac fatty acid metabolism in the mouse (27). LCAD was elevated in SHR cardiac mitochondria (121\%) (28).

Spot S8 was identified as heat-shock protein $\beta-1$ (HSPB1). HSPB1 was upregulated 1.9-fold in the EX-SHR group compared with the SED-SHR group as determined by 2D-PAGE. HSPB1, also known as HSP27, is a member of the mammalian heat-shock protein family (29). In smooth muscle cells, HSP27 appears to be the link between the signal transduction cascade and the contractile machinery (30). Park et al (31) reported lower HSP27 levels in plaques, lower levels of phosphorylation of HSP27 and higher plasma levels of secreted HSP27 in humans with acute coronary syndrome raised, in regards to the contribution of HSP27 in atherogenesis. Expression can increase in response to physical and chemical stressors including heat, mechanical strain, oxidative stress and proinflammatory mediators. Expression of small HSPs in 
striated and smooth muscle is frequently constitutive, but can also be modified by chemical or physical stressors (32).

Spot S9 was identified as isocitrate dehydrogenase (NAD) subunit $\alpha$. NAD subunit $\alpha$ was upregulated 1.9 -fold in the EX-SHR group compared with the SED-SHR group, as determined by 2D-PAGE. NAD-dependent isocitrate dehydrogenase, Idh, one of the eight enzymes of the Krebs cycle, is an octamer composed of Idh1p and Idh $2 p$ (encoded by IDH1 and IDH2, respectively) (33). In a previous study, the yeast enzyme was shown to be composed of two non-identical subunits, IDH1 and IDH2, with both being equally represented in the holoenzyme (34). These two subunits were shown to be essential for holoenzyme activity, since disruption of either or both genes encoding the subunits results in yeast strains that exhibit no detectable NAD1-specific isocitrate dehydrogenase activity and that are unable to grow with acetate as a carbon source (33). Research demonstrated that the yeast Krebs cycle enzyme IDH binds specifically and with high affinity to the 5 '-untranslated leader sequences of mitochondrial mRNAs in vitro and have proposed a role for the enzyme in the regulation of mitochondrial translation. Cells disrupted for the IDH genes exhibit a strong increase in mitochondrial translation activity and the newly synthesized products are also more rapidly degraded, which suggested that binding of Idh to mitochondrial mRNAs may suppress inappropriate translation of mitochondrial mRNAs (35). Research found significantly lower protein levels of IDH2 (93\%) and depressed total IDH activities (68\%) in SHR heart mitochondria. IDH1 appeared to have a higher level in SD rats undergoing 8 weeks of swimming training (36). IDH activity increased $32 \%$ in the 6 weeks of treadmill running in trained intermyofibrillar mitochondria (37).

Spot $\mathrm{S} 10$ was identified as actin, $\alpha$ cardiac muscle 1 preprotein. This preprotein was upregulated 1.9-fold in the EX-SHR group compared with the SED-SHR group as determined by $2 \mathrm{D}-\mathrm{PAGE}$. The highly conserved actins are the major constituents of the thin filaments in the muscle sarcomere. They are involved in force generation within the sarcomere and force transmission from the sarcomere to the surrounding syncytium (38). The $\alpha$-cardiac actin gene (ACTC) 1 is the major component of the sarcomeric thin filaments and is essential for cardiac muscle contraction. Knockdown of ACTC1 in chicks shows less developed atrial septa supporting a dose-dependent effect of ACTC1 on cardiac development. It has been suggested that the lack of ACTC1 may induce apoptosis leading to disrupted cardiac differentiation (39). ACTC was the first gene identified to harbor HCM and DCM mutations, with 6 mutations leading to $\mathrm{HCM}$ and 2 mutations leading to DCM (40).

Spot S11 was identified as calmodulin (CaM) isoform 2. CaM isoform 2 was downregulated by 1.8 -fold in the EX-SHR group compared with the SED-SHR group as determined by $2 \mathrm{D}$-PAGE. CaM is a calcium-binding protein which, when complexed with calcium, may mediate numerous calcium-dependent cellular activities (41). CaM is associated with a variety of cell functions including inflammation, apoptosis and muscular contraction. A previous study has shown that in the aorta from SHR, expression levels of several CaM-related proteins, including eukaryotic elongation factor kinase and death-associated protein kinase protein, increased, while $\mathrm{Ca}(2+) / \mathrm{CaM}$-dependent protein kinase II $\delta$ and histone deacetylases 4 protein decreased. CaM-related proteins may at least be in part associated with the pathogenesis of hypertensive vascular diseases (42).

In conclusion, proteomic analysis of proteins in the aortic wall from SHRs performing 6-week load-free swimming provided an effective approach for elucidating the molecular mechanisms of the exercise-induced blood pressure decrease. Eleven protein spots with different abundance were found, of which 9 differentially expressed proteins were identified by MALDI-TOF MS. The roles of these identified proteins in the exercise-induced blood pressure decrease were discussed. These findings provide information for understanding the mechanism of exercise decreasing blood pressure in the aortic wall.

\section{Acknowledgements}

The present study is supported in part by a grant from the National Natural Science Foundation of China (nos. 81171870 and 31470061), the Key Projects of Applied Basic and Frontier Technology Research of Tianjin (grant no. 14JCZDJC32700) and the Innovation Platform Special Program of Tianjin Science and Technology Innovation System.

\section{References}

1. Cavalcante JL, Lima JA, Redheuil A and Al-Mallah MH: Aortic stiffness: Current understanding and future directions. J Am Coll Cardiol 57: 1511-1522, 2011.

2. Aebersold R and Mann M: Mass spectrometry-based proteomics. Nature 422: 198-207, 2003.

3. Bian YL, Qi YX, Yan ZQ, Long DK, Shen BR and Jiang ZL: A proteomic analysis of aorta from spontaneously hypertensive rat: RhoGDI alpha upregulation by angiotensin II via AT(1) receptor. Eur J Cell Biol 87: 101-110, 2008.

4. Horta PP, de Carvalho JJ and Mandarim-de-Lacerda CA: Exercise training attenuates blood pressure elevation and adverse remodeling in the aorta of spontaneously hypertensive rats. Life Sci 77: 3336-3343, 2005.

5. Kimura H, Kon N, Furukawa S, Mukaida M, Yamakura F, Matsumoto K, Sone H and Murakami-Murofushi K: Effect of endurance exercise training on oxidative stress in spontaneously hypertensive rats (SHR) after emergence of hypertension. Clin Exp Hypertens 32: 407-415, 2010.

6. Bobillier Chaumont S, Maupoil V, Jacques Lahet J and Berthelot A: Effect of exercise training on metallothionein levels of hypertensive rats. Med Sci Sports Exerc 33: 724-728, 2001.

7. Zhang J, Ren CX, Qi YF, Lou LX, Chen L, Zhang LK, Wang X and Tang C: Exercise training promotes expression of apelin and APJ of cardiovascular tissues in spontaneously hypertensive rats. Life Sci 79: 1153-1159, 2006.

8. Bradford MM: A rapid and sensitive method for the quantitation of microgram quantities of protein utilizing the principle of protein-dye binding. Anal Biochem 72: 248-254, 1976.

9. Jenö P, Mini T, Moes S, Hintermann E and Horst M: Internal sequences from proteins digested in polyacrylamide gels. Anal Biochem 224: 75-82, 1995.

10. Song YJ, Sawamura M, Ikeda K, et al: Training in swimming reduces blood pressure and increase muscle transportactivity as well as GLUT 4 contents in stroke-prone spontaneously hypertensive rats. Appl Human Sci 17: 275-280, 1998.

11. Vogt M, Ott B, Rupp H and Jacob R: Significance of physical exercise in hypertension. Influence of water temperature and beta-blockade on blood pressure, degree of cardiac hypertrophy and cardiac function in swimming training of spontaneously hypertensive rats. Basic Res Cardiol 81 (Suppl 1): 157-169, 1986.

12. Zimmerman AW and Veerkamp JH: New insights into the structure and function of fatty acid-binding proteins. Cell Mol Life Sci 59: 1096-1116, 2002. 
13. Fu Y, Luo N and Lopes-Virella MF: Oxidized LDL induces the expression of ALBP/aP2 mRNA and protein in human THP-1 macrophages. J Lipid Res 41: 2017-2023, 2000.

14. Haunerland NH and SpenerF: Fatty acid-binding proteins-insights from genetic manipulations. Prog Lipid Res 43: 328-349, 2004.

15. Makowski L and Hotamisligil GS: The role of fatty acid binding proteins in metabolic syndrome and atherosclerosis. Curr Opin Lipidol 16: 543-548, 2005.

16. Lin QQ, Lin R, Ji QL, Zhang JY, Wang WR, Yang LN and Zhang KF: Effect of exercise training on renal function and renal aquaporin-2 expression in rats with chronic heart failure. Clin Exp Pharmacol Physiol 38: 179-185, 2011

17. Quinones QJ, de Ridder GG and Pizzo SV: GRP78: A chaperone with diverse roles beyond the endoplasmic reticulum. Histol Histopathol 23: 1409-1416, 2008.

18. González B, Hernando R and Manso R: Stress proteins of $70 \mathrm{kDa}$ in chronically exercised skeletal muscle. Pflugers Arch 440: 42-49, 2000.

19. Um HS, Kang EB, Leem YH, Cho IH, Yang CH, Chae KR, Hwang DY and Cho JY: Exercise training acts as a therapeutic strategy for reduction of the pathogenic phenotypes for Alzheimer's disease in an NSE/APPsw-transgenic model. Int J Mol Med 22: 529-539, 2008.

20. Murlasits Z, Lee Y and Powers SK: Short-term exercise does not increase ER stress protein expression in cardiac muscle. Med Sci Sports Exerc 39: 1522-1528, 2007.

21. Iozzo RV: The family of the small leucine-rich proteoglycans: Key regulators of matrix assembly and cellular growth. Crit Rev Biochem Mol Biol 32: 141-174, 1997.

22. Kampmann A, Fernández B, Deindl E, Kubin T, Pipp F, Eitenmüller I, Hoefer IE, Schaper W and Zimmermann R: The proteoglycan osteoglycin/mimecan is correlated with arteriogenesis. Mol Cell Biochem 322: 15-23, 2009.

23. Shanahan CM, Cary NR, Osbourn JK and Weissberg PL: Identification of osteoglycin as a component of the vascula matrix. Differential expression by vascular smooth muscle cells during neointima formation and in atherosclerotic plaques. Arterioscler Thromb Vasc Biol 17: 2437-2447, 1997.

24. Fernández B, Kampmann A, Pipp F, Zimmermann R and Schaper W: Osteoglycin expression and localization in rabbit tissues and atherosclerotic plaques. Mol Cell Biochem 246: 3-11, 2003.

25. Lea W, Abbas AS, Sprecher H, Vockley J and Schulz H: Long-chain acyl-CoA dehydrogenase is a key enzyme in the mitochondrial beta-oxidation of unsaturated fatty acids. Biochim Biophys Acta 1485: 121-128, 2000.

26. Cox KB, Hamm DA, Millington DS, Matern D, Vockley J, Rinaldo P, Pinkert CA, Rhead WJ, Lindsey JR and Wood PA: Gestational, pathologic and biochemical differences between very long-chain acyl-CoA dehydrogenase deficiency and long-chain acyl-CoA dehydrogenase deficiency in the mouse. Hum Mol Genet 10: 2069-2077, 2001.

27. van Vlies N, Tian L, Overmars H, Bootsma AH, Kulik W, Wanders RJ, Wood PA and Vaz FM: Characterization of carnitine and fatty acid metabolism in the long-chain acyl-CoA dehydrogenase-deficient mouse. Biochem J 387: 185-193, 2005.

28. Jüllig M, Hickey AJ, Chai CC, Skea GL, Middleditch MJ, Costa S, Choong SY, Philips AR and Cooper GJ: Is the failing heart out of fuel or a worn engine running rich? A study of mitochondria in old spontaneously hypertensive rats. Proteomics 8: 2556-2572, 2008.
29. Ciocca DR, Oesterreich S, Chamness GC, McGuire WL and Fuqua SA: Biological and clinical implications of heat shock protein 27,000 (Hsp27): A review. J Natl Cancer Inst 85: $1558-1570,1993$

30. Ibitayo AI, Sladick J, Tuteja S, Louis-Jacques O, Yamada H, Groblewski G, Welsh M and Bitar KN: HSP27 in signal transduction and association with contractile proteins in smooth muscle cells. Am J Physiol 277: G445-G454, 1999.

31. Park HK, Park EC, Bae SW, Park MY, Kim SW, Yoo HS, Tudev M, Ko YH, Choi YH, Kim S, et al: Expression of heat shock protein 27 in human atherosclerotic plaques and increased plasma level of heat shock protein 27 in patients with acute coronary syndrome. Circulation 114: 886-893, 2006.

32. Salinthone S, Tyagi M and Gerthoffer WT: Small heat shock proteins in smooth muscle. Pharmacol Ther 119: 44-54, 2008.

33. Cupp JR and McAlister-Henn L: Cloning and characterization of the gene encoding the IDH1 subunit of $\mathrm{NAD}(+)$-dependent isocitrate dehydrogenase from Saccharomyces cerevisiae. J Biol Chem 267: 16417-16423, 1992.

34. Keys DA and McAlister-Henn L: Subunit structure, expression, and function of $\mathrm{NAD}(\mathrm{H})$-specific isocitrate dehydrogenase in Saccharomyces cerevisiae. J Bacteriol 172: 4280-4287, 1990.

35. de Jong L, Elzinga SD, McCammon MT, Grivell LA and van der Spek H: Increased synthesis and decreased stability of mitochondrial translation products in yeast as a result of loss of mitochondrial $(\mathrm{NAD}(+))$-dependent isocitrate dehydrogenase FEBS Lett 483: 62-66, 2000.

36. Sun B, Wang JH, Lv YY, Zhu SS, Yang J and Ma JZ: Proteomic adaptation to chronic high intensity swimming training in the rat heart. Comp Biochem Physiol Part D Genomics Proteomics 3: 108-117, 2008.

37. Bizeau ME, Willis WT and Hazel JR: Differential responses to endurance training in subsarcolemmal and intermyofibrillar mitochondria. J Appl Physiol (1985) 85: 1279-1284, 1998.

38. Mogensen J, Klausen IC, Pedersen AK, Egeblad H, Bross P, Kruse TA, Gregersen N, Hansen PS, Baandrup U and Borglum AD: Alpha-cardiac actin is a novel disease gene in familial hypertrophic cardiomyopathy. J Clin Invest 103: R39-R43, 1999.

39. Matsson H, Eason J, Bookwalter CS, Klar J, Gustavsson P, Sunnegårdh J, Enell H, Jonzon A, Vikkula M, Gutierrez I, et al: Alpha-cardiac actin mutations produce atrial septal defects. Hum Mol Genet 17: 256-265, 2008

40. Mogensen J, Perrot A, Andersen PS, Havndrup O, Klausen IC, Christiansen $M$, Bross $P$, Egeblad $H$, Bundgaard $H$, Osterziel KJ, et al: Clinical and genetic characteristics of alpha cardiac actin gene mutations in hypertrophic cardiomyopathy. J Med Genet 41: e10, 2004.

41. Van Breemen C,Aaronson P and Loutzenhiser R: Sodium-calcium interactions in mammalian smooth muscle. Pharmacol Rev 30: 167-208, 1978.

42. Usui T, Okada M, Hara Y and Yamawaki H: Exploring calmodulin-related proteins, which mediate development of hypertension, in vascular tissues of spontaneous hypertensive rats. Biochem Biophys Res Commun 405: 47-51, 2011. 